ARTIGO ORIGINAL

\title{
Influências, implicações e resquícios das proposições didático-pedagógicas críticas da Educação Física escolar brasileira na Base Nacional Comum Curricular

\author{
Influences, implications and remnants of the critical didactic-pedagogical propositions of \\ Brazilian Physical Education in the National Curricular Common Base
}

\author{
Larissa Gandarela, Bianca Raquel dos Santos Silveira, Beatriz Barreto e Silva, \\ Josefa Graziele Santos Santana, Laís Vitória Souza Silva Santos, Cristiano Mezzaroba \\ Universidade Federal de Sergipe (UFS), Aracaju, Brasil
}

\section{HISTÓRICO DO ARTIGO \\ Recebido: 12 junho 2021 \\ $1^{\text {a }}$ Revisão: 17 agosto 2021 \\ 2a Revisão: 17 outubro 2021 \\ Aprovado: 18 outubro 2021}

\section{PALAVRAS-CHAVE:}

Educação física escolar;

Proposições didático-pedagógicas;

Base Nacional Comum Curricular.

\section{KEYWORDS:}

School Physical Education;

Didactic-pedagogical propositions; National Common Curriculum Base.

\section{RESUMO}

OBJETIVO: Analisar as possíveis convergências e dissonâncias entre as proposições didático-pedagógicas críticas da Educação Física (EF) e a Base Nacional Comum Curricular (BNCC), buscando compreender se há alguma influência das proposições na formulação deste documento.

MÉTODOS: Utilizou-se da pesquisa de cunho qualitativo do tipo análise documental com caráter descritivoexploratório.

RESULTADOS: A partir do que analisamos no decorrer da pesquisa obtivemos resultados com relação às semelhanças entre a BNCC e as proposições críticas, tais como a organização dos conteúdos, a necessidade de problematização do esporte, a educação integral, a interdisciplinaridade e os eixos norteadores do processo de aula, como as dimensões do conhecimento, habilidades e competências. Para além disso, também foram identificadas algumas diferenças, como a visão crítica de mundo, apresentada pelas proposições e a visão voltada para o mundo do trabalho, proposta pela BNCC, além da ausência da participação dos alunos na construção das aulas na BNCC e a falta de procedimentos metodológicos no documento.

CONCLUSÃO: Em suma, podemos perceber ao longo da BNCC os resquícios e contribuições das proposições críticas, entretanto, é possível notar a falta de elementos da EF construídos historicamente pelas proposições. A BNCC se apresenta como um avanço no que se refere às normativas educacionais, porém pode ser vista como um retrocesso em relação às conquistas históricas no campo da EF.

\section{ABSTRACT}

OBJECTIVE: To analyze the possible convergences and dissonances between the critical didactic-pedagogical propositions of Physical Education (PE) and the National Common Curricular Base (NCCB), seeking to understand if there is any influence of the propositions in the formulation of this document.

METHODS: We used qualitative research of the documentary analysis type with a descriptive-exploratory nature.

RESULTS: From what we analyzed in the course of the research, we obtained results regarding the similarities between the NCCB and the critical propositions, such as the organization of the contents, the need to problematize sport, integral education, interdisciplinarity and the guiding axes of the process of classes, as well as the dimensions of knowledge, abilities and competences. In addition, some differences were also identified, such as the critical view of the world, presented by the propositions and the view towards the world of work, proposed by NCCB, in addition to the absence of student participation in the construction of classes in the NCCB and the lack of methodological procedures in the document.

CONCLUSION: In short, we can see throughout the NCCB the remnants and contributions of the critical propositions, however, it is possible to notice the lack of elements of PE historically built by the propositions. NCCB presents itself as an advance in terms of educational standards, but it can be seen as a setback in relation to historical achievements in the field of PE. 


\section{INTRODUÇÃo}

O campo da Educação Física (EF) escolar, desde a década de 1980, vem sendo motivo de debates e discussões acadêmicas em torno da sua legitimidade enquanto componente curricular. Com a eclosão das chamadas "proposições didático-pedagógicas críticas" no âmbito da EF, iniciou-se um movimento assíduo de busca pela superação do modelo, predominantemente técnico e voltado para uma perspectiva desenvolvimentista, pautada nos aspectos físicos e biológicos do corpo e do movimento (DARIDO, 2003).

Neste contexto, diversos estudiosos se propõem a pensar uma "nova" EF, que não esteja apenas atribuída a uma finalidade biológica, mas que colabore, sobretudo, na formação cidadã do aluno. Essas propostas tiveram as mais diversas denominações, como "metodologias críticas" ou mesmo "proposições críticas" ou "abordagens críticas", sendo que as mais conhecidas são as chamadas "Crítico-Superadora" (SOARES et al., 1992; 2012), "Aulas Abertas às experiências dos alunos" (HILDEBRANDT; LAGING, 1986, 2005; GRUPO DE TRABALHO PEDAGÓGIGO UFPE-UFSM, 1991) e "Crítico-Emancipatória" (KUNZ, 1991; 1994), cada uma com suas características próprias, com objetivos de estudo, método e base teórica diferentes, porém, todas problematizando quanto à necessidade do ensino da EF a partir de um enfoque no ser humano crítico, emancipado e livre, para além da dimensão biológica, como até então a EF era pensada e praticada.

No plano da legalização dessas propostas, podemos considerar que foi principalmente a partir de 1996, com a promulgação da LDB - Lei de Diretrizes e Bases da Educação, em específico quanto à publicação do artigo 26 da LDB no 9394/1996, que passava a considerar a EF como um componente curricular da educação básica (BRASIL, 1996). Com isso, os debates em torno da sua funcionalidade pedagógica se intensificaram e a busca por uma organização curricular, que fundamentassem os pressupostos pedagógicos desse campo, passou a ser considerado o foco principal das discussões acadêmicas no âmbito da EF escolar (BOSCATTO; IMPOLCETTO; DARIDO, 2016).

A partir desta perspectiva, a criação de uma Base Nacional Comum Curricular (BNCC), que sistematizasse os conhecimentos básicos que deveriam ser tematizados em cada nível de ensino e estimulasse a ideia de progressividade do conhecimento ao longo dos anos escolares, em todas as instituições escolares brasileiras, guardando certas particularidades regionais/locais, surge como uma solução política para o que era considerado uma desorganização conceitual e didático-pedagógica, que fundamentava o campo da EF escolar.

Dessa forma, principalmente no campo da EF, em que existiam diferentes perspectivas teórico-metodológicas, a BNCC é vista, para alguns, como um documento político que tira a liberdade e autonomia dos professores, delimita os conteúdos e ignora questões culturais. Enquanto para outros, é considerado como meio para estruturar e elucidar os aspectos didáticos deste componente curricular, no que diz respeito ao seu objeto de estudo, seus conteúdos e os seus objetivos, garantindo, no plano nacional, minimamente uma unidade de saberes e fazeres (NEIRA, SOUZA JÚNIOR, 2016; TRICHES, ARANDA, 2016; NEIRA, ALVIANO JÚNIOR, ALMEIDA, 2016).

Evidente que como diversos professores/pesquisadores par- ticiparam do processo de criação da BNCC, a fundamentação teórica utilizada para a sua elaboração possui embasamentos conceituais de outros autores que já constituíam o campo, antes da sua criação. Sendo assim, podemos identificar na BNCC, seja de forma explícita ou implícita, algumas particularidades das proposições didático-pedagógicas, desenvolvidas principalmente por Soares et al. (1992; 2012), por Kunz (1994) e por Hildebrandt e Laging (1996; 2005), entre outros.

Tratando-se de um documento normativo que passou a reger a educação nacional, como seu próprio nome indica, de servir como um currículo que aponte uma "base nacional" comum aos diferentes contextos regionais brasileiros, consideramos que é importante conhecer e compreender a sua concepção, elaboração, contexto, ideologia implícita e explícita, papel e função dentro da sociedade.

Apesar de ser um documento recente, já existe um considerável quantitativo de produções que, de alguma forma, buscaram evidenciar como o componente curricular EF é apresentado na BNCC, como os estudos de Callai, Becker e Sawitzki (2019), Martinelli, Magalhães, Mileski e Almeida (2016) e Pinheiro (2018). No entanto, ainda é possível identificar uma escassez de pesquisas que analisaram a fundamentação teórica utilizada pela BNCC para definir os princípios que devem reger esse campo do conhecimento (NEIRA, SOUZA JÚNIOR, 2016; NEIRA, 2018), e, com relação ao tema proposto até o momento de produção deste artigo, não foram encontradas outras pesquisas.

Assim, o objetivo geral deste estudo é analisar as possíveis convergências e dissonâncias entre as proposições didático-pedagógicas críticas da EF e a BNCC, no Ensino Fundamental, buscando compreender se há alguma influência destas abordagens na formulação deste documento.

Na sequência do texto, apresentaremos os aspectos metodológicos do presente estudo, em seguida, faremos uma breve síntese sobre as proposições "Crítico-Superadora" (SOARES et al., 1992; 2012), "Aulas Abertas às experiências dos alunos" (HILDEBRANDT; LAGING, 1986, 2005; GRUPO DE TRABALHO PEDAGÓGIGO UFPE-UFSM, 1991) e "Crítico-Emancipatória" (KUNZ, 1991; 1994). Depois, iremos expor desde a criação da BNCC até aspectos específicos da EF. Por fim, realizaremos uma discussão sobre as interrelações entre essas proposições e a BNCC, procurando pensar nas implicações e possibilidades atuais para EF a partir do documento.

\section{MÉTODOS}

Essa pesquisa trata de um aprofundamento teórico sobre a BNCC, com uma análise a partir das proposições didático-pedagógicas críticas da EF, logo, é uma pesquisa do tipo documental e bibliográfica, envolvendo a análise tanto da BNCC como também do conjunto teórico-conceitual e metodológico contido nas proposições conhecidas como crítico-superadora, crítico-emancipatória e aulas abertas.

Além disso, o estudo classifica-se dentro de uma abordagem qualitativa, que segundo Minayo (2002), refere-se a uma pesquisa em que os resultados não são apontados através de números ou de viés quantitativo, mas de interpretações subjetivas provindas do olhar do pesquisador sobre o significado do que está sendo analisado, que no caso desta pesquisa, trata-se da BNCC e sua sistematização e usos a partir do que já havia sido 
construído no campo da EF escolar brasileira.

Buscamos analisar a BNCC a partir de uma pesquisa de cunho exploratório, que segundo Minayo (2002) tende a explorar através de uma reflexão crítica os dados levantados, entendendo-os enquanto partes que compõem um objeto em sua totalidade e desse modo levantar e tensionar as diversas possibilidades e temáticas que o preenche, não objetivando o alcance de um resultado de forma concreta, ou seja, o propósito não é de confirmação ou geração de leis próprias, mas com valorização da perspectiva de descoberta.

Desenvolvemos a pesquisa inicialmente a partir dos conhecimentos anteriores sobre as obras das três proposições pedagógicas, muito debatidas nas aulas de graduação em Licenciatura em Educação Física (conforme nossa própria experiência), então nos dedicamos a ler a BNCC e a identificar pontos de similaridades, assim como aspectos dissonantes. E logo partimos para uma análise mais profunda sobre as proposições e o documento, fazendo uma releitura das obras e de pesquisas sobre o tema. Com isso, começamos a construção da pesquisa sobre as características de cada uma das proposições e da BNCC. Posteriormente, introduzimos a análise a partir das semelhanças encontradas entre cada proposição didático-pedagógica individualmente com relação à BNCC.

\section{RESULTADOS E DISCUSSÃO}

Retomando as proposições didático-pedagógicas críticas: elementos de uma EF humanista e progressista

Historicamente marcada por um discurso médico-higienista, militarista e esportivista, a EF, por muito tempo, foi considerada apenas como uma mera atividade realizada dentro do âmbito escolar. Na LDB de 1971, por exemplo, é atribuído à EF a designação de "atividade". A partir dessa perspectiva, a disciplina passa a ser compreendida, seja no âmbito acadêmico ou no senso comum, apenas como um campo prático, que não necessita de uma reflexão teórica (IMPOLCETTO; DARIDO, 2017).

Buscando dar um novo rumo ao campo da EF escolar, a partir da década de 1980, diversos autores começam a refletir e propor mudanças pedagógicas, que visavam demonstrar que, enquanto um componente curricular, a EF deve contribuir na formação integral (social, cultural, físico e intelectual) do sujeito. Esse movimento de mudança, que ficou conhecido como Movimento Renovador da Educação Física Brasileira, objetivava romper com o modelo mecanicista, biologicista e tecnicista que predominava nas aulas de EF da época, atribuindo à disciplina o papel de contribuir pedagogicamente, não só no desenvolvimento físico e motor do aluno, mas também na formação social, cultural e humana, assim como as outras disciplinas escolares (DARIDO, 2003).

Embora já existissem modelos teórico-metodológicos para as aulas de $\mathrm{EF}$, para além do modelo esportivizante que prezava pela alta performance, bem como da Psicomotricidade, do Desenvolvimentismo e da abordagem Construtivista-interacionista, foi com o Movimento Renovador que passaram a ser elaboradas proposições didático-pedagógicas críticas na EF escolar, que visavam colaborar, sobretudo, com a formação social dos estudantes, como a concepção crítico-superadora (SOARES et al., 1992; 2012), a concepção crítico-emancipatória (KUNZ,
1991; 1994) e de aulas abertas às experiências de ensino (HILDEBRANDT; LAGING, 1986; 2005; GRUPO DE TRABALHO PEDAGÓGIGO UFPE-UFSM, 1991). E é destas três propostas que trataremos, trazendo seu contexto histórico e suas características didático-pedagógicas, para, em seguida, articularmos tais conhecimentos em relação à BNCC.

\section{Proposição das Aulas Abertas às experiências de ensino}

A proposta de aulas abertas, cujo idealizadores são Reiner Hildebrandt e Ralf Laging $(1986,2005)$, além do Grupo de TrabaIho Pedagógigo UFPE-UFSM (1991) que adaptou a proposta inicial para o campo educacional brasileiro, é caracterizada como sendo uma tendência educacional progressista que tem como objeto de estudo o mundo do movimento e suas implicações sociais.

Segundo Hildebrandt e Laging (2005), podemos sintetizar as aulas abertas a partir da seguinte explicação:

\section{As concepções de ensino são abertas quando os alunos partici- pam das decisões em relação aos objetivos, conteúdos e âmbitos de transmissão ou dentro deste complexo de decisões. O grau de abertura depende do grau de possibilidades de co-decisão. As pos- sibilidades de decisão dos alunos são determinadas cada vez mais pela decisão prévia do professor (HILDEBRANDT; LAGING, 2005, p. 15).}

A abordagem de aulas abertas tem como objetivo principal proporcionar, a partir da tematização subjetiva e significativa dos aspectos envolvidos no movimento, a formação de sujeitos criativos, responsáveis, comunicativos, críticos e autônomos, que tenham todas as competências necessárias para agir ativamente no âmbito social. Para isso, é importante considerar a relação entre movimento, percepção e realização (HILDEBRANDT; LAGING, 2005). Ou seja, a abordagem de aulas abertas considera o movimento como algo que deve ser percebido pelo aluno em toda sua amplitude, atribuindo sentidos e significados que estão para além de apenas um gesto mecânico, como por exemplo, quando se ensina o esporte a partir de sua dimensão técnica.

Essa abordagem coloca o aluno não como um receptor ou um objeto a ser "manipulado" pelo professor para atingir determinados objetivos, mas como um sujeito ativo nas decisões didático-pedagógicas envolvidas no processo de ensino-aprendizagem (HILDEBRANDT; LAGING, 2005). Esse ideário que coloca o aluno no centro do processo é resultado de uma linha de pensamento não-diretiva, defendida pela Pedagogia Libertária de Paulo Freire, que retira do professor o monopólio das decisões educacionais (LIRA NETO, 2008).

Em suma, o Grupo de Trabalho Pedagógico das Universidades Federais de Pernambuco e Santa Maria (1991, p. 40), ressalta que as aulas fechadas se orientam "[...] no professor; no produto; nas metas definidas e na intenção racionalista" e aulas abertas se orientam "[...] no aluno; no processo; na problematização; e na comunicação" (GRUPO DE TRABALHO PEDAGÓGIGO UFPE-UFSM, 1991, p. 40).

\section{Proposição Crítico-Superadora}

Posteriormente à proposição de aulas abertas (quando consideramos as datas de publicação das obras aqui utilizadas), surge a concepção denominada "crítico-superadora", a qual foi 
desenvolvida por um conjunto de professores que ficou conhecido no campo da EF brasileira como "Coletivo de autores", os quais pretendiam, a partir dessa metodologia, atingir o desenvolvimento de uma consciência crítica perante a realidade social, visando assim, uma transformação da realidade.

Para Soares et al. (2012), o objeto de estudo da EF é a cultura corporal, a qual refere-se às práticas corporais desenvolvidas pelas sociedades ao longo da história. Tais conhecimentos devem ser considerados como uma forma de linguagem e devem transpor a expressão corporal de uma dada cultura.

Tal proposição é denominada dessa forma pois pretende superar o sistema capitalista através do desenvolvimento de um senso crítico. Desse modo, pretendia-se (e pretende-se) promover aulas com teor histórico-crítico, a fim de responder aos interesses da classe trabalhadora, promovendo uma reflexão sobre a realidade social, buscando superá-la de modo a alcançar um mundo mais justo e igualitário.

A referida proposição defende que o foco do currículo deve ser a reflexão do aluno e, por isso, os autores defendem a lógica de um currículo ampliado, considerando que os conhecimentos devem ser apresentados de forma inter-relacionada às demais áreas do conhecimento, promovendo desse modo uma visão da totalidade da realidade social.

A crítico-superadora traz como conteúdo as práticas corporais na forma de jogos, esportes, ginástica, danças, brincadeiras, capoeira, lutas, malabarismo, esportes de aventura, entre outros, visando apreender a expressão corporal como linguagem.

Além disso, os proponentes desta proposição apresentam alguns princípios que devem nortear o processo educativo, dentre eles, a necessidade de entender que todo conteúdo tem um tempo pedagogicamente necessário para a sua apreensão de acordo com as individualidades e com o desenvolvimento sociocognitivo, por isso a abordagem apresenta de que forma se pode trabalhar cada conteúdo de acordo com o ciclo, abordando-o de forma espiralada.

\section{Proposição Crítico-Emancipatória}

Nesse contexto de mudanças dentro da área da $E F$, surge também a abordagem crítico-emancipatória. Desenvolvida por Elenor Kunz a partir de um estudo de caso sobre as aulas de EF de duas escolas no interior do Rio Grande do Sul, as quais tinham as aulas configuradas a partir do desenvolvimento do esporte de rendimento e o tecnicismo, com foco nos atletas que possuíam habilidades naquela modalidade, abordando de forma superficial ou excludente sobre os demais (KUNZ, 1994).

Kunz (2000) critica esse modelo de aula excludente e tecnicista, ele não contesta o uso do esporte como conteúdo das aulas, porém, não concorda com a maneira como ele é utilizado. Para Kunz (2000), a EF tem como objeto de estudo a cultura do movimento, possibilitando a formação do aluno de uma maneira reflexiva, crítica, objetiva e subjetiva.

A proposição chama-se "crítico-emancipatória" porque, segundo Kunz (2000), o termo "crítico" diz respeito à "[...] capacidade de avaliação e análise intersubjetiva das condições de racionalidade" (KUNZ, 2000, p. 33); enquanto o termo "emancipação" se refere a "[...] esse processo de libertar o jovem das condições que limitam o uso da razão crítica e com isso todo o seu agir social cultural e esportivo, que se desenvolve pela edu- cação" (KUNZ, 2000, p. 33).

A proposição considera que o ensino deve proporcionar o esclarecimento dos indivíduos a fim de possibilitar um processo de libertação das falsas ilusões da indústria cultural, como em relação ao esporte de alto rendimento e sua espetacularização. Para que isso seja possível, o autor apresenta estratégias para a estruturação das aulas, a qual ele intitula como "transcendências de limites". Além disso, Kunz (1994) apresenta os arranjos materiais e a utilização de materiais recicláveis como uma importante ferramenta para a compensação no déficit de técnicas mais elaboradas.

Contudo, tal proposição só pode ser desenvolvida a partir da "ação comunicativa", a qual pode ser compreendida como a consequência da relação de sujeitos, capazes de dialogarem e através do entendimento atingirem a compreensão das situações em que se inserem e os seus planos de ações. Sendo a ação comunicativa um ponto central para que o aluno seja um sujeito ativo no processo de aprendizagem e possa se desenvolver enquanto um indivíduo no processo de emancipação humana (KUNZ, 1994).

\section{Surge a BNCC - Marcos Legais}

A BNCC (BRASIL, 2017) é um documento normativo que regula toda a Educação Básica do país, tendo como objetivo o nivelamento dos conteúdos em todo território nacional nas diversas instituições, públicas e privadas de nível municipal, estadual ou federal.

A utilização desses conteúdos para o ensino fundamental já está prevista desde a Constituição de 1988, no artigo 210, quando determina que: "Serão fixados conteúdos mínimos para o ensino fundamental, de maneira a assegurar formação básica comum e respeito aos valores culturais e artísticos, nacionais e regionais" (BRASIL, 1988).

Em 1996 é regulamentada a BNCC na LDB, Lei 9.394 (BRASIL, 1996), cujo texto concorda que devem ser estabelecidas competências e diretrizes para a Educação Básica, para que se possa guiar os currículos e seus conteúdos, garantindo a formação básica. Em seguida, de 1998 até 2000, são criados pelo Ministério da Educação os PCN's (Parâmetros Curriculares Nacionais), documento que passou a orientar os professores, até então, porém, sem o caráter obrigatório.

A primeira versão da BNCC disponibilizada em 2015, provocou uma grande mobilização das escolas e universidades de todo Brasil para discussão do documento preliminar, o qual foi aberto à consulta pública. O mesmo aconteceu em 2016 com a segunda versão do documento (BRASIL, 2017). Entretanto, a terceira versão, que está em vigor, sofreu algumas alterações sem consulta pública, havendo a exclusão de temas como raça, gênero e sexualidade, sendo que tais mudanças ocorreram em meio a um contexto de grande turbulência no contexto político, considerando o processo de impeachment de 2016, o qual traz ao poder um grupo político de ideais conservadores (CÁsSIO, 2018).

Importante destacar que é impossível atingir a imparcialidade, principalmente se tratando de um documento normativo. Entretanto, não possuímos o intuito de focar nesse debate, tendo em vista que ele já está implícito na nossa tentativa de comparação entre o documento e as proposições críticas. 


\section{A estrutura da Base Nacional Comum Curricular}

A BNCC está estruturada de forma que os níveis de ensino são entendidos por etapas. Inicialmente, a Educação Infantil, com seus direitos de aprendizagem, desenvolvimento e os campos de experiências aplicados a bebês ( $0 \mathrm{~m}-1 \mathrm{a} 6 \mathrm{~m})$, crianças bem pequenas (1a7m-3a11m) e crianças pequenas (4a-5a11m). 0 Ensino Fundamental, com as áreas do conhecimento, as competências específicas de cada área, os componentes curriculares e as competências específicas dos componentes, dos anos iniciais (1음 aㅇ) até os finais (6으 ao 9ㅇ), possuindo suas unidades temáticas, os objetos de conhecimentos de cada uma e as habilidades. E por fim, o Ensino Médio, com as áreas do conhecimento e as competências específicas até as habilidades.

A BNCC no Ensino Fundamental possui cinco áreas do conhecimento, contendo seus componentes curriculares: na área das Linguagens entram como componentes a Língua Portuguesa, Língua Inglesa, Educação Física e Arte; na área da Matemática, está a componente Matemática; nas Ciências da Natureza está a Ciência; dentro das Ciências Humanas, a Geografia e a História; e na área do Ensino Religioso está o Ensino Religioso.

Já as competências gerais, conforme a BNCC, "[...] devem ser desenvolvidas ao longo de toda a Educação Básica e em cada etapa da escolaridade, como expressão dos direitos de aprendizagem e desenvolvimento de todos os estudantes" (BRASIL, 2017, p. 23). Além de serem apresentadas de forma geral, são trazidas a partir de cada nível de ensino, assim como estão presentes no Ensino Fundamental, em cada área de conhecimento e nos componentes curriculares de forma específica, mas todas partindo das competências gerais. Tais competências devem ser desenvolvidas pelos alunos no decorrer dos anos iniciais até os finais, para o desenvolvimento das habilidades nos alunos necessárias para sua inserção no convívio social.

Seguindo a organização do conhecimento escolar, cada componente curricular é organizado por unidades temáticas, objetos de conhecimento (conteúdos, conceitos e processos) e habilidades (aprendizagens essenciais estabelecidas a depender do contexto escolar), de acordo com o nível de ensino, separado por blocos, do fundamental menor e fundamental maior, sendo que cada componente curricular divide-se de uma forma específica. Tendo a compreensão de que a aprendizagem se dá de forma gradativa, as habilidades, que estão interligadas com as competências, são organizadas de modo que sejam abordadas em cada nível de ensino progressivamente, dos conhecimentos mais simples para os mais complexos.

\section{A Educação Física na BNCC}

A EF está posta na Área de Linguagens da BNCC por trabaIhar com a linguagem corporal, justifica-se sua colocação na área a partir do pressuposto de que as práticas corporais fazem parte da linguagem não verbal, as quais irão fazer com que os alunos possam desenvolver, experimentar e viver momentos, conhecimentos e práticas únicas (BRASIL, 2017).

Compreende-se, assim, que a BNCC tem como objeto de estudo a ser trabalhado na Educação Física a Cultura corporal de movimento, pois considera as práticas corporais como elemento que está ligado às ciências humanas, atribuindo ligações/ relações entre as práticas corporais e a cultura, como aparece no documento: "[...] as práticas corporais são textos culturais passíveis de leitura e produção" (BRASIL, 2017, p. 210). Assim, as práticas corporais podem ser tematizadas em suas várias formas de codificação e significado social.

As práticas corporais estão diretamente ligadas com as Unidades Temáticas, tendo como sugestão para o Ensino Fundamental: Brincadeiras e jogos, Danças, Esportes, Ginásticas: do 1 으 ao 9 ano; Lutas: do 3ㅇa ao 9o ano e Práticas corporais de aventura: 60 ao 90 ano. A BNCC frisa que a normativa serve como sugestão para o currículo, ou seja, ele pode ser alterado de acordo com a necessidade e características de cada lugar. Elas devem possibilitar ao estudante construir e reconstruir um arsenal de conhecimentos que permitam a ampliação da sua consciência em relação a seus movimentos e aos recursos de cuidado de si e dos outros, além de desenvolver autonomia para a apropriação e utilização da cultura corporal de movimento.

Conforme Daolio (2004), o termo cultura corporal de movimento, muito utilizado por autores das abordagens críticas, como Valter Bracht $(1992 ; 1999)$ e Mauro Betti (1994), surge após a transformação do objeto da EF, que inicialmente era o motor, passando pelo psicológico, social, e chegando no ser cultural, muito debatido atualmente. Porém, o termo ainda traz conceitos diferentes, baseados nas fundamentações teóricas de cada autor, sendo alguns fundamentados na Antropologia Social, outros na Antropologia Filosófica ou na Sociologia.

Ainda é retratado na BNCC as dimensões do conhecimento, as quais norteiam o ensino da EF e devem ser trabalhadas pelo professor na aula de forma interligada, fazendo com que os alunos possam adquiri-las com o decorrer das aulas. São elas: experimentação, uso e apropriação, fruição, reflexão sobre a ação, construção de valores, análise, compreensão e protagonismo comunitário.

\section{Analisando possíveis implicações, influências e resquícios das proposições críticas da EF brasileira na BNCC}

Por se tratar de um documento normativo que visa estabelecer os conteúdos e as aprendizagens básicas de cada etapa do ensino e não determinar os procedimentos metodológicos dos profissionais da área (BRASIL, 2017), é importante entender como a BNCC, enquanto documento normativo destinado a sistematizar todos componentes curriculares em todo âmbito nacional, se apropria e apresenta (de maneira implícita ou explícita) os pressupostos teórico-metodológicos que fundamentam o debate teórico, praxiológico e pedagógico do campo que foi construído e acumulado historicamente, observável, por exemplo, nas três concepções teórico-metodológicas aqui consideradas (aulas abertas, crítico-superadora e crítico-emancipatória). Deste modo, detalharemos as inter-relações estabelecidas entre a BNCC e as proposições críticas da EF, já contextualizadas.

Destacamos que por estarmos analisando o documento em relação às três concepções críticas da $E F$, as quais guardam em si diferenças, é necessário apontar, desde já, que algumas inter-relações tornam-se difíceis e até mesmo impossíveis de serem realizadas.

A princípio, em relação ao desenvolvimento dos conteúdos dentro do processo de ensino, a BNCC não apresenta métodos que orientem o ensino dos conteúdos obrigatórios, tem como foco principal uma organização e sistematização dos conteúdos 
da EF, ou seja, prioriza "o que ensinar" e "em que momento", em detrimento de "como ensinar" e de "por que ensinar" (embora para essas duas últimas, podemos pensar em aproximações quanto às oito dimensões do conhecimento, mas são inferências possíveis, não apontadas no documento). Importante destacar que, por ser um documento normativo, não poderia trazer um método específico obrigatório, considerando que se deve ter assegurado dentro do processo educacional a diversidade de concepções pedagógicas (BRASIL, 1996).

Ao traçarmos um paralelo possível das questões metodológicas da BNCC com a abordagem crítico-superadora, esta traz uma prática de ensino que acontece de forma espiralada, com uma ampliação contínua dos conhecimentos e aspectos próprios em relação ao desenvolvimento da aula e avaliação. Em relação às aulas abertas, os alunos se apresentam como foco desde a construção da aula, participando da escolha dos conteúdos, criação e reconstrução das aulas. E quanto à crítico-emancipatória, a "ação comunicativa" mostra-se como eixo dentro do processo metodológico, destacando sempre a necessidade de troca comunicativa horizontalizada entre professor e aluno.

Quando nos detemos aos pressupostos teórico-epistemológicos, identificamos que a abordagem crítico-superadora é embasada pelo materialismo histórico-dialético, buscando um ensino libertador, com foco nas lutas de classes (SOARES et al., 2012), que apesar de em alguns pontos a BNCC apontar dimensões históricas, antropológicas e sociológicas, explicita-se, na BNCC, que, no geral, o objetivo da formação escolar é manter "o mercado do trabalho" com conhecimento técnico, ou seja, uma perspectiva conformista dentro dos pressupostos do sistema capitalista mundial.

A concepção crítico-emancipatória visa a emancipação do jovem, a liberdade e o conhecimento crítico, aspectos que também são identificados na BNCC, na área das dimensões do conhecimento, as quais envolvem o social, a questão democrática e a liberdade. Entretanto, quando analisamos o documento de maneira mais aprofundada, é perceptível um foco na formação, na área de trabalho, um conhecimento funcional. Poderíamos considerar que, por querer dar acesso a um ensino básico para todos, tendo em vista que o acesso ao conhecimento é uma forma de possibilitar a emancipação dos sujeitos, ela de certa forma busca essa emancipação, porém, essa ideia não sustenta a proximidade com a proposta crítico-emancipatória, cuja autonomia é sustentada a partir dos ideais kantianos e de referencial pautado na Teoria Crítica da Escola de Frankfurt e também de base na Teoria do Agir Comunicativo de Habermas (KUNZ, 1994).

Com relação à proposição das aulas abertas, a base da construção dessa metodologia é a participação ativa do aluno, considerando desde os conteúdos selecionados para a construção e desenvolvimento da aula, bem como, a preocupação com o objetivo principal desta concepção libertária de referencial pautado em Paulo Freire, que é formar sujeitos autônomos e participantes na sociedade. Já a BNCC traz de forma subjetiva pontos que dão liberdade à participação dos alunos, entretanto, não tem na sua estrutura uma participação ativa na formação e no desenvolvimento da aula, a única unidade temática que apresenta certa abertura para a contribuição dos alunos é a unidade "Jogos e Brincadeiras", na qual propõe uma reformulação das práticas pelos próprios alunos, entretanto, de uma forma super- ficial, não possibilitando sua participação no planejamento da aula, o que a diferencia da metodologia de aulas abertas.

As competências gerais da BNCC são elementos importantes a serem observados, assim como, as abordagens críticas, que atribuem à EF escolar o papel de contribuir na formação de sujeitos socialmente ativos e participantes das decisões envolvidas no contexto em que ele está inserido. Nesse sentido, na BNCC podemos perceber essa preocupação no momento em que o documento afirma que a $\mathrm{EF}$ escolar, enquanto componente curricular, deve "[...] desenvolver autonomia para apropriação e utilização da cultura corporal de movimento em diversas finalidades humanas, favorecendo sua participação de forma confiante e autoral na sociedade" (BRASIL, 2017, p. 213, grifos nossos). No entanto, é possível identificar que a BNCC apresenta uma perspectiva de autonomia voltada para o campo do lazer e da saúde, suprimindo a participação da EF na formação de sujeitos autônomos no âmbito das relações sociais (BRASIL, 2017).

Outro ponto importante a ser discutido sobre a BNCC são as oito dimensões do conhecimento, considerando que algumas delas estão presentes no decorrer do que é apresentado nas proposições críticas, porém, acabam sendo expressas de forma implícita ou a partir da utilização de outros termos. Logo, mostra-se a influência das proposições na construção do documento da EF na BNCC.

Uma das dimensões expostas na BNCC é a "experimentação", a qual está relacionada com o desenvolvimento subjetivo das práticas corporais dos alunos nas aulas a serem realizadas (BRASIL, 2017). Com isso, podemos inferir que há aproximações entre a "experimentação" enquanto dimensão do conhecimento na BNCC com a forma como a proposta de aulas abertas vai considerar a oferta de múltiplas experiências corporais, na forma de "mundo de movimento", que, segundo Hildebrandt-Stramann apud Hirai e Cardoso (2009) sugerem a utilização do vasto campo de diferentes experiências do movimento. Assim como também pode ser associada aos pressupostos da concepção crítico-emancipatória, já que Kunz (1994), retrata essa questão da experimentação nas transcendências de limites em que há o uso da experimentação dos alunos nas práticas corporais.

Outra dimensão que está de acordo com as proposições metodológicas críticas é a "reflexão sobre a ação", a qual está ligada com os conhecimentos obtidos a partir da vivência corporal, sendo feita uma reflexão para aplicar possíveis mudanças e estratégias com relação às práticas (BRASIL, 2017). A reflexão sobre a ação pode ser compreendida como uma questão da problematização, a qual pode acarretar um "conhecimento de si" e também diz que deve ser provocada sempre que houver a possibilidade de instigar o processo de voltar-se a si para refletir sobre a dimensão dos conteúdos (KUNZ apud HIRAI; CARDOSO, 2009).

A problematização na educação brasileira é oriunda das contribuições do pedagogo Paulo Freire, que, conforme Hirai e Cardoso (2009, p. 108), "[...] orienta para a adoção da educação problematizadora, compreendendo que é por tal ensino que acontecerá a libertação, sendo as problematizações sociais/ culturais o meio em que se dará o compromisso." É perceptível que esse elemento freiriano impacta fortemente nas concepções de Kunz (1994) e de Hildebrandt e Laging (1986), as quais retratam e trabalham o desenvolvimento crítico no aluno, além de ser identificado na obra de Soares et al. (1992), para os quais, 
é a partir do tensionamento reflexivo e problematizador que a transformação social pode acontecer. Diferente da BNCC, que traz a reflexão sobre a ação com o intuito de manter o foco da formação escolar tendo como objetivo final uma preparação para o mercado de trabalho.

Também é possível analisar a dimensão do "protagonismo comunitário" presente na BNCC, que se refere à capacidade de reflexão sobre as possibilidades de acesso e participação de práticas corporais na sua realidade social. Deste modo, fica evidente uma aproximação de tal dimensão do conhecimento em relação aos pressupostos da proposição crítico-superadora, em que se destaca a busca do desenvolvimento de seres conscientes e socialmente ativos.

Assim como na perspectiva da proposição das aulas abertas, a BNCC também considera o trabalho coletivo como uma importante estratégia formativa para ser utilizada nas aulas de EF, o que pode ser evidenciado na competência de número 10 da BNCC, em que é apontada a necessidade de abordar as práticas corporais, de modo que seja valorizado o trabalho em grupo e o protagonismo.

Além disso, a proposição de aulas abertas considera que o professor deve adotar procedimentos metodológicos não-diretivos, no qual o aluno aprende a partir da descoberta e da solução de problemas, temas ou tarefas. E, apesar da BNCC não apontar, explicitamente, as estratégias metodológicas que devem ser utilizadas nas aulas, é possível identificar, na competência de número 2, aproximação quanto a tal estratégia, pois há a seguinte redação quanto ao trabalho com os alunos: "Planejar e empregar estratégias para resolver desafios e aumentar as possibilidades de aprendizagem das práticas corporais [...]" (BRASIL, 2017, p. 223). A partir disso, concluímos que é fundamental que o professor desafie os alunos com diferentes tarefas, tirando-os da zona de conforto e os estimulando a pensar em melhores estratégias e soluções.

No entanto, são estabelecidos na BNCC códigos e determinações, que dificultam a utilização desse pressuposto não-diretivo em que ao estabelecer quais conteúdos e habilidades que os alunos devem adquirir no decorrer da aula, ou em cada nível de ensino, a BNCC demonstra ir na contramão de uma perspectiva que dá centralidade ao aluno e ao processo, como pauta a perspectiva das aulas abertas, já que de acordo com essa perspectiva educacional, o objetivo do ensino deve ser focado no aluno e nas suas particularidades, sendo que nesse processo o professor é apenas um facilitador de uma aprendizagem, que deve ser, imprescindivelmente, significativa para o aluno.

Neira (2018) não concorda com a forma que a BNCC especifica o que deve e quando deve ser ensinado determinado conteúdo ao aluno. Ressalta que é importante conhecer os conteúdos básicos da EF (esportes, jogos, danças, ginástica, lutas e brincadeiras), mas, não da maneira que se é imposta pelo documento, pois a BNCC não conhece como vivem, o que pensam, o que fazem cada estudante do Brasil, isto é, torna-se necessário considerar aspectos singulares, a partir dos aspectos locais e regionais e seus contextos possíveis.

Com relação aos conteúdos, a proposição crítico-emancipatória foca no debate da adaptação do esporte, do esporte "da" escola, no sentido não institucionalizado, e sim partindo de um sentindo da experimentação, da reflexão, da criticidade, assim como ocorre com a proposição das aulas abertas. Já na proposição crítico-superadora e na BNCC, é possível observar a presença dos temas clássicos da EF, ambas trazem esses conteúdos como "práticas corporais" e como "unidades temáticas", respectivamente. Contudo, notam-se pequenas variações para além dos conteúdos hegemônicos, por exemplo, a crítico-superadora possibilita que malabares, atividades circenses e capoeira sejam classificadas como "práticas corporais", entretanto, quando se trata da BNCC, nota-se a necessidade de classificar todos os conteúdos de acordo com as unidades temáticas estabelecidas, não apresentando grande flexibilidade para novos conteúdos.

As proposições procuram entender os conteúdos como algo mutável de acordo com os contextos históricos, sociais, culturais e pedagógicos. Por exemplo, a crítico-superadora busca trabalhar os conteúdos a partir de um cunho histórico e da realidade social de cada indivíduo, e por isso, conteúdos podem ser acrescentados de acordo com o contexto social. Na crítico-emancipatória e nas aulas abertas também se visualiza uma flexibilidade em relação aos conteúdos (não são propositivas e sistematizadas), considerando que se mostra importante entender as experiências e vivências dos indivíduos, e deste modo, os conteúdos se adequam às possibilidades dos sujeitos.

Porém, em relação à BNCC, identifica-se uma estrutura na organização dos conteúdos que não possibilita espaço para alterações e implementações de novos conteúdos, dificultando as adequações aos diferentes contextos, o que pode ser visto por parte do campo da EF como um aspecto positivo, porque, enfim, passamos a ter uma sistematização, mas, por outro lado, outros setores da EF identificam nessa sistematização um fechamento quanto a outras possibilidades de trabalhar outros conteúdos não-hegemônicos.

Um ponto em comum, entre as proposições aqui analisadas no que se refere aos conteúdos, diz respeito à compreensão do esporte enquanto conteúdo a ser tematizado e problematizado, considerando que as práticas esportivas devam ir além do desenvolvimento físico e técnico, sendo necessário, assim, ser adaptado para o contexto escolar, e não apenas reproduzido de acordo com os princípios que regem o esporte de rendimento.

Em relação à referência que a BNCC faz ao esporte, pode-se destacar que o documento retrata tal elemento com o caráter de formas derivadas, fazendo uma referência ao esporte de rendimento padrão e ao adaptado para a realidade escolar, assim como é citado nas habilidades EF67EF07, EF67EF05 e EF67EF06. Se pensado em relação às proposições críticas da $E F$, a dimensão crítica possível em relação ao conteúdo esportivo - por ser a prática corporal hegemônica do mundo moderno - perde em possibilidade de reflexão, crítica e transformação pedagógica.

Outro princípio educativo presente na BNCC, encontrado na Introdução do documento, diz respeito à importância da integração entre as disciplinas escolares, no qual é indicado a necessidade de se pensar um ensino em que os componentes curriculares estejam interligados e não de forma isolada ou dissociável. É indicado no documento que é necessário que sejam adotadas estratégias pedagógicas que articulem os conhecimentos que serão tematizados em cada nível escolar, de modo que os alunos consigam perceber a relação existente entre os conhecimentos adquiridos durante o processo de ensino-aprendizagem (BRASIL, 2017, p. 16).

Essa perspectiva de ensino, pautada na interdisciplinarida- 
de do currículo, também é defendida por Soares et al. (1992), em que é compreendido como objeto do currículo a reflexão do aluno, e para isso, entendem que a reflexão é gerada a partir da realidade social através de determinada lógica, por isso se defende um currículo ampliado, em que cada disciplina promove a reflexão do aluno, inter-relacionando o conhecimento da sua área com as demais áreas do conhecimento, promovendo nele uma visão de totalidade da realidade social e com isso leva a compreensão que nenhuma disciplina se legitima de forma isolada.

Assim como na BNCC, que ao considerar as manifestações da cultura local dos alunos, demonstra essa compreensão do social e do cultural como determinante para o ensino, as abordagens críticas mencionam a necessidade de compreender o contexto social como um importante determinante para se pensar o ensino escolar. A abordagem de aulas abertas, por exemplo, a partir de uma perspectiva de legitimação humana, considera que os aspectos metodológicos devem considerar as experiências individuais e os conhecimentos prévios dos alunos, ou seja, os movimentos particulares, que são realizados cotidianamente fora da escola (GRUPO DE TRABALHO PEDAGÓGICO UFPE-UFSM, 1991).

A partir de tais reflexões percebemos que, apesar de diferentes proposições virem tematizando ao longo dos anos o que deveria ser proposto na EF escolar, enquanto componente curricular da educação básica, as reflexões resultantes desses debates ainda vêm sendo pouco exploradas quanto a uma consolidação na implementação de tais propostas dentro dos documentos que regem esse campo.

Sendo assim, como uma forma de provocar novas reflexões e investigações sobre o tema, encerramos essa análise com a seguinte indagação: por que, ao se lançar um documento normativo que contemple todo território brasileiro, bem como, que considere a riqueza histórica que vem se acumulando no campo pedagógico e sociocultural da EF brasileira, passa-se a silenciar construções críticas e progressistas que, se implementadas e consolidadas no contexto escolar, poderiam garantir a presença de uma EF com viés mais social e cultural no trato com seus conteúdos nas escolas?

\section{CONSIDERAÇÕES FINAIS}

A presente pesquisa objetivou analisar as possíveis convergências e dissonâncias entre as proposições didático-pedagógicas críticas da EF e a BNCC, no Ensino Fundamental, buscando compreender se há alguma influência destas abordagens na formulação deste documento. A partir desta investigação foi possível constatar que, apesar de percebemos alguns aspectos semelhantes entre a BNCC e as proposições críticas da EF, também foi possível encontrar elementos que divergem das particularidades que compõem as proposições. Apesar de não ter utilizado nomeadamente as proposições críticas como o seu referencial teórico, podemos perceber, ao longo da BNCC, seus resquícios e contribuições.

Em síntese, as proposições críticas da EF, aqui apresentadas, indicam-nos diversas possibilidades de construir um processo de ensino-aprendizagem, que não objetive apenas o desenvolvimento físico e motor (como defendido outrora), mas que considere as subjetividades de cada aluno. Sendo assim, ciente da necessidade de pensarmos uma nova EF Escolar, que contribua para a formação do aluno em todas as suas dimensões, é importante compreendermos e considerarmos as várias abordagens pedagógicas que norteiam esse campo de atuação, antes mesmo da criação da BNCC. No entanto, percebemos aqui que, mesmo que em alguns pontos existam determinadas aproximações entre a BNCC e as proposições didático-pedagógicas críticas/progressistas formuladas no início da década de 1990, em muitos aspectos identificamos um distanciamento ou mesmo um silenciamento deste documento em relação às proposições aqui analisadas.

Ao se lançar um documento normativo que contemple todo território brasileiro, optou-se por silenciar um debate histórico com relação aos conhecimentos teóricos, críticos e reflexivos (os quais eram o maior enfoque das proposições críticas), que, se implementados e consolidados no contexto escolar, poderiam garantir a presença de uma EF com viés mais social e cultural. Sendo assim, cabe nos questionarmos se a BNCC seria um avanço, no que diz respeito ao processo de renovação da $\mathrm{EF}$ enquanto componente curricular, ou um retrocesso? Encerraremos este texto com esse questionamento, importante e necessário para entendermos a necessidade de implementar tal documento dentro do contexto escolar e dos desafios impostos pela contemporaneidade.

\section{REFERÊNCIAS}

BETTI, M. O que a semiótica inspira ao ensino da educação física. Discorpo, São Paulo, n. 3, p. 25-45, 1994.

BRACHT, V. Educação física e aprendizagem social. 2. ed. Porto Alegre: Magister, 1992.

BRACHT, V. A constituição das teorias pedagógicas da educação física. Caderno CEDES, São Paulo, v. 19, n. 48, p. 69-88, 1999.

BRASIL. Constituição da República Federal do Brasil de 1988. Disponível em: <http://www.planalto.gov.br/ccivil 03/constituicao/constituicao.htm>. Acessado em: 12 maio 2021.

BRASIL. Lei no 9.394, de 20 de dezembro de 1996. Estabelece as Diretrizes e Bases da Educação Nacional. Diário Oficial da União, Brasília, DF. Disponível em: <http://www.planalto.gov.br/ccivil 03/leis/19394.htm>. Acessado em: 11 de maio de 2021.

BRASIL. Ministério da Educação. Base Nacional Comum Curricular. Brasília: MEC/CONSED, 2017. Disponível em: <http://basenacionalcomum.mec.gov. br/images/BNCC EI EF 110518 versaofinal site.pdf>. Acessado em: 11 de maio de 2021.

BRASIL. Ministério da Educação e Cultura. Lei no 5.692, de 11 de agosto de 1971. Fixa diretrizes e bases para o ensino de 1ㅇ e 2 o graus, e dá outras providências. Diário Oficial da República Federativa do Brasil, Brasília, DF, 12 ago. 1971. Disponível em: <https://www2.camara.leg.br/legin/fed/ lei/1970-1979/lei-5692-11-agosto-1971-357752-publicacaooriginal-1-pl. html>. Acessado em: 11 de maio de 2021.

BOSCATTO, J. D.; IMPOLCETTO, F. M.; DARIDO, S. C. A Base Nacional Comum Curricular: uma proposição necessária para a educação física? Motrivivência, Florianópolis, v. 28, n. 48, p. 96-112, 2016.

CALLAI, A. N. A.; BECKER, E. P.; SAWITZKI, R. L. Considerações acerca da educação física escolar a partir da BNCC. Conexões, Campinas, v. 17, p. 1-16, 2019.

CASSIO, F. L. Base Nacional Comum Curricular: ponto de saturação e retrocesso na educação. Revista Retratos da Escola, Brasília, v. 12, n. 23, p. 239-53, 2018.

DAOLIO, J. Educação física e o conceito de cultura. Campinas: Autores Associados, 2004.

DARIDO, S. C. Educação física na escola: questões e reflexões. Rio de Janeiro: Guanabara Koogan, 2003.

GRUPO DE TRABALHO PEDAGÓGICO UFPE-UFSM. Visão didática da 
educação física: análises críticas e exemplos práticos de aulas. Rio de Janeiro: Livro Técnico, 1991.

HILDEBRANDT-STRAMANN, R.; LAGING, R. Concepções abertas no ensino da educação física. Rio de Janeiro: Ao Livro Técnico, 1986.

HILDEBRANDT-STRAMANN, R.; LAGING, R. Concepções abertas ao ensino da educação física. 2. ed. Rio de Janeiro: Ao Livro Técnico, 2005.

HIRAI, R. T.; CARDOSO, L. C. Possibilidades para o ensino orientado na problematização: para a realização da concepção de "aulas abertas às experiências". Movimento, Porto Alegre, v. 15, n. 1, p. 1-18, 2009.

IMPOLCETTO, F. M.; DARIDO, S. C. Organização curricular na educação física escolar. Revista Brasileira de Educação Física e Esporte, São Paulo, v. 31, n. 3, p. 601-17, 2017

KUNZ, E. Educação física: ensino \& mudanças. ljui: Unijui, 1991.

KUNZ, E. Transformação didático-pedagógica do esporte. 5. ed. ljui: Unijui, 1994.

LIRA NETO, J. F. Relações entre a proposta das concepções abertas no ensino da educação física e o método Paulo Freire. Conexões, Campinas, v. 6, n. 2 , p. $62-81,2008$

MARTINELI, T. A. P.; MAGALHÃES, C. H.; MILESKI, K. G.; ALMEIDA, E. M. de. A educação física na BNCC: concepções e fundamentos políticos e pedagógicos. Motrivivência, Florianópolis, v. 28, n. 48, p. 76-95, 2016.

MINAYO, M. C. Pesquisa social: teoria, método e criatividade. 21.ed. Petrópolis: Vozes, 2002.

NEIRA, M. G. Incoerências e inconsistências da BNCC de educação física. Revista Brasileira de Ciências do Esporte, São Paulo, v. 40, n. 3, p. 216-23, 2018.

NEIRA, M. G.; SOUZA JUNIOR, M. S. A Educação física na BNCC: procedimentos, concepções e efeitos. Motrivivência, v. 28, n. 48, p. 188206, 2016.

NEIRA, M. G.; ALVIANO JUNIOR, W. A.; ALMEIDA D. F. de. A primeira segunda versões da BNCC: construção, intenções e condicionantes. EccoS São Paulo, n. 41, p. 31-44, 2016

PERRENOUD, P. O que fazer da ambiguidade dos programas escolares orientados para as competências. Pátio Revista Pedagógica, Porto Alegre, v. 23, p. $8-11,2002$.

PINHEIRO, E. G. A Educação física escolar na Base Nacional Comum Curricular: dinâmicas de um movimento em construção. 2018. 381f Dissertação (Mestrado em Educação Física) - Universidade Estadual de Maringá, Maringá, 2018

ROCHA, M.; SILVA, H.; SILVA, D. Educação integral e escola em tempo integral: em busca da formação emancipadora. Revista de Pesquisa Interdisciplinar Cajazeiras, n. 2, Sup., p. 354-65, 2017.

SOARES, C. L.; TAFFAREL, C. N. Z.; VARJAL, M. E. M. P.; CASTELLLANI FILHO, L.; ESCOBAR, M. O.; BRACHT, V. Metodologia do ensino de educação física. São Paulo: Cortez, 1992

SOARES, C. L.; TAFFAREL, C. N. Z.; VARJAL, M. E. M. P.; CASTELLLANI FILHO, L.; ESCOBAR, M. O.; BRACHT, V. Metodologia do ensino de educação física. 2. ed. São Paulo: Cortez, 2012

TRICHES, E. de F; ARANDA, M. A. de M. A formulação da Base Nacional Comum Curricular (BNCC) como ação da política educacional: breve levantamento bibliográfico (2014-2016). Revista Online de Extensão e Cultura Realização, Dourados, v. 3, n. 5, p. 81-98, 2016.

VAGO, T. M. O "esporte na escola" e o "esporte da escola": da negação radical para uma relação de tensão permanente - Um diálogo com Valter Bracht. Movimento, Porto Alegre, v. 3, n. 5, p. 4-17, 1996.

\section{CONFLITO DE INTERESSE}

Os autores do estudo declaram não haver conflito de interesses.

\section{FINANCIAMENTO}

Este estudo não teve apoio financeiro.

\section{ORCID E E-MAIL DOS AUTORES}

Larissa Gandarela (Autor Correspondente) ORCID: 0000-0002-8022-9619. E-mail: larissa_ganda@hotmail.com

Bianca Raquel dos Santos Silveira ORCID: 0000-0001-7550-6768.

E-mail: biancarssilveira@gmail.com

Beatriz Barreto e Silva

ORCID: 0000-0002-9728-3064.

E-mail: beatrizbarreto08@gmail.com

Josefa Graziele Santos Santana

ORCID: 0000-0001-6473-4802.

E-mail: grazielesantossantana945@gmail.com

Laís Vitória Souza Silva Santos

ORCID: 0000-0003-0471-4732

E-mail: laisouzza02@gmail.com

Cristiano Mezzaroba

ORCID: 0000-0003-4214-0629.

E-mail: cristiano_mezzaroba@yahoo.com.br 